\title{
Monitoring trends in sexual behaviour in Zambia, 1996-2003
}

\author{
E Slaymaker, B Buckner
}

Sex Transm Infect 2004;80(Suppl II):ii85-ii90. doi: 10.1136/sti.2004.012054

See end of article for authors' affiliations

....................

Correspondence to: Ms E Slaymaker, Centre for Population Studies, London School of Hygiene and Tropical Medicine, 49-51 Bedford Square, London WCIB 3DP, UK; emma.slaymaker@ Ishtm.ac.uk

Accepted for publication 2 August 2004
Objectives: This paper assesses the evidence of changes in sexual behaviour in Zambia, accounting for differences in the composition of survey samples and for evidence of changes in reporting bias. It compares the estimates of sexual behaviour measures obtained using two different survey methodologies. Methods: Data from five nationally representative household surveys carried out between 1996 and 2003 were analysed for change in selected sexual behaviours.

Results: There is some evidence for an increase in men's age at first sex. The proportion of people reporting multiple partnerships and not using a condom at last sex has declined since 1996. Unprotected sex with non-cohabiting partners is reported less frequently in the later surveys. The socioeconomic and demographic composition of the survey samples has changed across the years but the declines in behaviour remain statistically significant after adjustment for these changes. There is evidence of a changing reporting bias over the period of interest, with respondents less likely to report a young age at first sex in later surveys.

Conclusions: Between 1996 and 2003, reported sexual behaviour has changed in Zambia among both men and women. Different survey methods produce significantly different estimates of sexual behaviour. This must be taken into account when carrying out trend analyses using data from different sources.
1 has been suggested that the HIV prevalence measured through sentinel surveillance at some antenatal clinic sites in Zambia has begun to decline. ${ }^{1}$ It has also been suggested that sexual behaviour has changed in the recent past. ${ }^{1-3}$ It is to be hoped that these data reflect real changes and that fewer people in Zambia are engaging in risky sexual behaviours that permit HIV transmission. However, there are alternative explanations for apparent decreases in both HIV prevalence and risky sexual behaviours. Pregnant women who attend an antenatal clinic that participates in sentinel surveillance are not necessarily a representative sample of all adults. The extent to which HIV prevalence among pregnant women can be used as a proxy for HIV prevalence in the general population may have changed. Apparent changes in sexual behaviours between surveys may result from different methodologies, or changes in the way respondents report their behaviour, but not in the way they behave.

Data gathered in five household surveys conducted between 1996 and 2003 were analysed for evidence of changes in sexual behaviour and to assess whether any observed changes can be explained by changes in the sociodemographic composition of successive samples. Where possible, the likelihood that the changes are due to changes in reporting bias is assessed.

The surveys used in this analysis are nationally representative household surveys which interviewed respondents of reproductive age and included questions about sexual behaviour and knowledge of HIV/AIDS prevention. Details of these surveys are given in table 1. The 1996 and 2002 surveys were Zambia Demographic and Health Surveys (DHS). ${ }^{4}$ The surveys in 1998, 2000, and 2003 were Sexual Behaviour Surveys (SBS) ${ }^{6-8}$ carried out by the Central Statistical Office with technical assistance from the MEASURE Evaluation project, funded by USAID, and Project Concern International. Zambia is remarkable in having carried out five such surveys in seven years. The two styles of survey differed in focus. The DHS covered a wider range of topics and included the questions on sexual behaviour towards the end of the survey. The SBS was solely concerned with sexual behaviour and HIV/AIDS related topics and so questions about sexual behaviour were asked early in the interview.

The objectives of this paper are to ascertain whether sexual behaviour has changed between 1996 and 2003, using data from the five household surveys and taking into account differences in survey design and sample composition. Specific questions are:

(1) Has the reported age at first sex increased, and is this likely to be the result of a change in propensity to report early sex?

(2) Are fewer people engaging in unprotected sex with noncohabiting partners in 2003 compared with 1996?

(3) Are fewer people having sex with more than one partner in the course of a year in 2003 compared with 1996?

(4) Has condom use changed between 1996 and 2003?

(5) Do the two different survey styles (DHS and SBS) produce comparable estimates of key indicators of sexual behaviour?

\section{METHODS}

The objectives, organisation, sample design, and questionnaires used in the five surveys have been described in detail elsewhere. $^{4-8}$ All were nationally representative household surveys of adult men and women.

All the samples were stratified, the 18 strata formed by the urban and rural areas of each province. In 1996 the DHS used a three stage sampling strategy. The primary sampling units (PSU) were census supervisory areas (based on the 1990 census) and within each PSU a census enumeration area was selected. Households in the enumeration area were selected and a listing of household members was drawn up. All women aged 15-49 years were eligible for interview and in

Abbreviations: DHS, Demographic and Health Surveys; PSU, Primary Sampling Units; SBS, Sexual Behaviour Surveys. 
Table 1 Surveys used in this analysis with the number of male and female respondents and response rates

\begin{tabular}{|c|c|c|c|c|c|c|}
\hline \multirow{2}{*}{$\begin{array}{l}\text { Type of } \\
\text { survey }\end{array}$} & \multirow[b]{2}{*}{ Year } & \multicolumn{2}{|c|}{$\begin{array}{l}\text { Number of } \\
\text { respondents }\end{array}$} & \multicolumn{3}{|c|}{$\begin{array}{l}\text { Percentage of those eligible } \\
\text { that were interviewed }\end{array}$} \\
\hline & & Women & Men & Households & Men* & Women* \\
\hline $\mathrm{DHS}^{5}$ & 1996 & 8021 & 1849 & 99 & 91 & 97 \\
\hline $\mathrm{SBS}^{6}$ & 1998 & 2040 & 1655 & 97 & 92 & 95 \\
\hline $\mathrm{SBS}^{7}$ & 2000 & 1926 & 1521 & 92 & 85 & 88 \\
\hline $\mathrm{DHS}^{4}$ & $2001-02$ & 7658 & 2168 & 98 & 89 & 96 \\
\hline $\mathrm{SBS}^{8}$ & 2003 & 2326 & 2147 & 93 & 85 & 87 \\
\hline
\end{tabular}

*Eligible respondents identified from the listing of members in interviewed households.

every fourth household all men aged 15-59 years were eligible for the survey. Three provinces were over sampled and weights were applied to the data to permit the calculation of correct national estimates.

The sample frame for the 1998 SBS was the 312 PSU used in the 1996 DHS. Eighty of these were selected at random and within each PSU the household listings were updated and households were sampled at random from this list. All men and women aged 15-49 years were eligible for interview. The 2000 SBS used the same sampling procedure.

The 2001-2002 DHS used a new two stage sampling strategy based on the 2000 census. The PSU were census enumeration areas within which households were selected. All women aged 15-49 years were eligible for interview and in one third of households all men aged 15-59 years were also eligible.

The 2003 SBS used the same methods as previous SBS. Where possible the original PSU from the 1998 and 2000 surveys were retained, and new sampling points were added, drawn from the same frame used in the 2000 SBS.

A preliminary analysis was carried out on each data set using the information on sample design and weighting appropriate to each survey. The sociodemographic composition of each survey sample was described, and selected indicators of sexual behaviour were constructed. The indicators were chosen to reflect both recent and lifetime behaviours, and to describe patterns of risky sexual behaviour among both married and unmarried respondents. Retrospective data on age at first sex were used to assess changes over time. Current status data were used to assess the level of sexual experience among young people (defined as those aged 15-24 years inclusive). The highest risk behaviours were defined as sex between non-cohabiting partners who did not use a condom, and sex with multiple partners without using a condom (both measured over a 12 month reference period). Sex between non-cohabiting partners is one of the key indicators of sexual risk behaviour defined by WHO/ UNAIDS. ${ }^{9}$ Sex with multiple partners is a key epidemiological determinant of the epidemic.

Data from all the surveys were combined for multivariate analysis. Distinctions were made between the PSU used in the first three surveys and those used in the second DHS and in the latter SBS, even though some of the same PSU were used in all surveys. ${ }^{10}$ The original strata and sample weights were retained throughout. All analyses were carried out using Stata version 8 (Stata Corporation, College Station, TX, USA).

\section{RESULTS}

\section{Survey design}

The distribution of respondents by province does not differ in the five surveys. Table 1 shows response rates for women, men, and households. National rates were generally high but response rates for both men and women, in both 1996 and
2001-2002, varied markedly by province, ${ }^{45}$ this information is not available for the other surveys.

\section{Sociodemographic characteristics of the survey samples}

The numbers of respondents are given in table 1 . The upper age limit for male respondents was higher than for female respondents ( $59 v 49$ years) except in the 1998 SBS where the upper limit was 49 years for both sexes. The large differences in sample size for men and women in the two DHS arise from the decision to interview only a subsample of men. The 2000 SBS included some respondents aged less than 15 years who were excluded from this analysis. The survey samples became progressively older and the age distribution changed significantly over time, even allowing for the different age boundaries. The percentage of men and women currently working varied markedly over the surveys. The religious affiliation of the respondents also changed, but this may result partly from different coding of responses in the "other" category.

\section{Sexual behaviour}

\section{Proportion that have ever had sex}

The proportion of women aged 15-24 years who reported having had sex was very similar in all five surveys (table 2). As shown in figure 1 about a quarter of 15 year old women reported having had sex in the 1996-2002 surveys; in 2003, this proportion decreases to $15 \%$. The proportion of women who report ever having sex rises rapidly to include about $80 \%$ of 18 year olds in the earlier surveys. Percentages are 5-8\% lower in the 2002 and 2003 surveys for 18 year olds, and 5\% lower for 19 year olds in all three surveys in the years 20002003. By the age of 24 , over $95 \%$ of Zambian women have become sexually active.

The proportion of young men (aged 15-24 years) who reported having had sex varies considerably. The proportion of 15 year old men who reported having had sex dropped from 35\% in the 1996 survey to $14 \%$ in the 2003 SBS. This proportion increased between the two DHS surveys (from $35 \%$ in 1996 to $48 \%$ in 2002), but showed a clear pattern of decline in the three SBS surveys (from 37\% in 1998 to $14 \%$ in 2003). In the 1996 survey, the proportion of young men who said they had had sex increased rapidly over the next three years of age, with three quarters of men reporting having had sex by age 18. The increase is slower in all later surveys, and especially so in the 2000 and 2003 SBSs, with less than $60 \%$ of 18 year old men saying they have had sex. There were still some men (about 5\%) who say they have not started having sex by age 24 .

To investigate further the striking trends for men a logistic regression model was fitted to examine the trend over time while controlling for differences between the survey samples. Table 3 gives these results. There is a significant decline over time, with young men $7 \%$ less likely to report having had sex in each year after 1996, the baseline. The type of survey (DHS compared with SBS) was important, and men were more likely to report having had sex in the DHS-independent of the decline over time.

\section{Proportion who report having had sex by age 15}

Declines in the proportion of respondents reporting first sex before the age of 15 years were most pronounced in the DHS (see table 2). In the 1996 survey 24\% of women and 30\% of men reported early sex compared with $19 \%$ of women and men in 2001-2002. In the SBS approximately 15\% of women in all three surveys and 19\% of men in the 1998 and 15\% of men in the subsequent surveys reported sex before age 15. A logistic regression model was fitted to assess the role of confounding and the results are shown in table 3. 

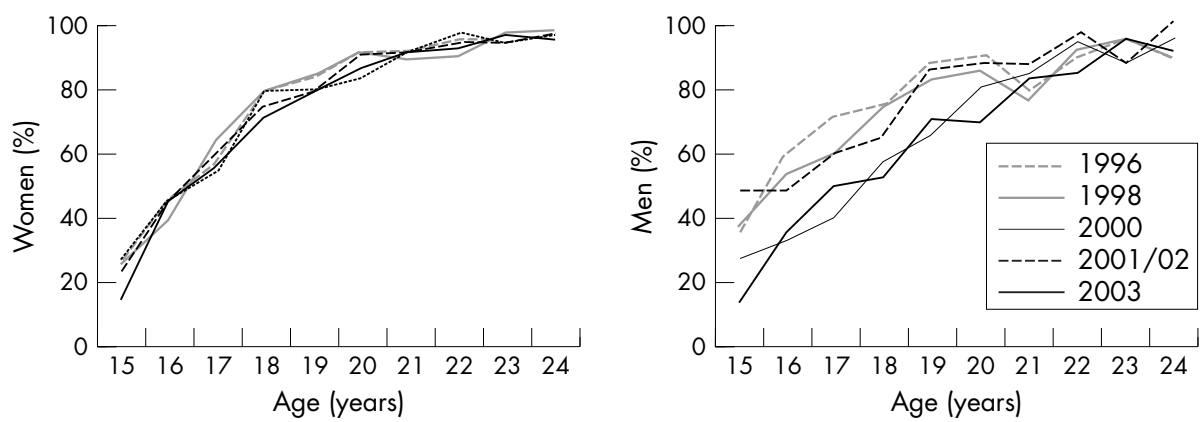

Figure 1 Percentage of people aged 15-24 years who report having had sex, by survey.

Declines in the reporting of sex before the age of 15 are significant for men and women after controlling for sociodemographic characteristics. However, there is evidence that these declines are at least partially due to a change in reporting bias. A real change would be apparent as a cohort effect but the patterns of reporting are not entirely consistent with this. Figure 2 shows the proportion of respondents reporting sex by the age of 15 in the 1996 and 2001-2002 surveys by their age in 1996. The estimates from the two surveys should be almost the same because the behaviour of these people cannot have changed between the surveys. A cohort effect would be evident as a decline in the younger age groups compared with the older age groups and there is some suggestion of this for women. Figure 2 suggests that a change in propensity to report early sex has taken place in Zambia.

Sex with non-cohabiting partners, sex with cohabiting partners, and condom use

Survey samples can be divided into categories based on ascending risk behaviour in the year preceding the survey. Six categories are used to describe sex and condom use between cohabiting and non-cohabiting partners. The denominator for each category is all respondents. The categories are: never had sex; had sex but not in the last year; had sex in the last year with a cohabiting partner only and used a condom on the most recent occasion; had sex in the last year with a cohabiting partner only and did not use a condom on the most recent occasion; had sex in the last year with a noncohabiting partner and used a condom on the most recent occasion; had sex in the last year with a non-cohabiting partner and did not use a condom on the most recent occasion.

When subdivided in this way the distribution of the survey population among these behaviour categories is different for men and women and varies by age group. In all years, the majority of women in all age groups report having had sex with a cohabiting partner only, or with no-one at all, in the 12 months before the survey. Among men, sex with a cohabiting partner only is less common. It is not until their late 20s that sex with a cohabiting partner only becomes the dominant behaviour among men. In 1996, among those who had sex with a non-cohabiting partner, the use of a condom on the last occasion is reported more commonly by men than by women. Across all age groups, men are about twice as likely as women to say they used a condom last time. Almost half of the men in their 20s and 30s who had sex with a noncohabiting partner in the last year say they used a condom on the most recent occasion, compared with $30 \%$ of the 1519 year olds, and $27 \%$ of those in their early 40 s. Condom use was least common among men in their late 40 s (14\%).

Over time the pattern remains similar for women. There is a small reduction in the size of the group who report having had sex with a non-cohabiting partner without using a condom on the last occasion (see table 2). There are increases

Table 2 Selected indicators of sexual behaviour in five survey samples

\begin{tabular}{|c|c|c|c|c|c|c|}
\hline Indicator & $\%$ & 1996 & 1998 & 2000 & 2001 & 2003 \\
\hline \multirow[t]{2}{*}{$\begin{array}{l}\text { Ever had sex } \\
\text { (15 to } 24 \text { year olds) }\end{array}$} & Men & $\begin{array}{l}89 \\
(86.9-90.8)\end{array}$ & $\begin{array}{l}87.9 \\
(85.6-89.9)\end{array}$ & $\begin{array}{l}87.1 \\
(84.7-89.1)\end{array}$ & $\begin{array}{l}90.6 \\
(89.1-91.8)\end{array}$ & $\begin{array}{l}85.4 \\
(83.3-87.2)\end{array}$ \\
\hline & Women & $\begin{array}{l}88.2 \\
(87.3-89.1)\end{array}$ & $\begin{array}{l}88.3 \\
(86.4-90.0)\end{array}$ & $\begin{array}{l}88.7 \\
(86.7-90.5)\end{array}$ & $\begin{array}{l}88.2 \\
(87.0-89.2)\end{array}$ & $\begin{array}{l}88.1 \\
(86.5-89.6)\end{array}$ \\
\hline \multirow[t]{2}{*}{ Sex by 15} & Men & $\begin{array}{l}29.6 \\
(27.0-32.3)\end{array}$ & $\begin{array}{l}19 \\
(16.3-22.0)\end{array}$ & $\begin{array}{l}15.3 \\
(13.0-17.9)\end{array}$ & $\begin{array}{l}19.3 \\
(17.3-21.5)\end{array}$ & $\begin{array}{l}15.4 \\
(13.7-17.1)\end{array}$ \\
\hline & Women & $\begin{array}{l}23.5 \\
(22.3-24.8)\end{array}$ & $\begin{array}{l}14.6 \\
(12.4-17.1)\end{array}$ & $\begin{array}{l}14.4 \\
(12.1-17.0)\end{array}$ & $\begin{array}{l}19.3 \\
(18.1-20.5)\end{array}$ & $\begin{array}{l}14.4 \\
(12.7-16.3)\end{array}$ \\
\hline \multirow{2}{*}{$\begin{array}{l}\text { Sex with non-cohabiting } \\
\text { partner in last year; no } \\
\text { condom last time }\end{array}$} & Men & $\begin{array}{l}25.3 \\
(23.1-27.6)\end{array}$ & & $\begin{array}{l}13.6 \\
(11.3-16.1)\end{array}$ & $\begin{array}{l}19.9 \\
(17.9-22.1)\end{array}$ & $\begin{array}{l}12.3 \\
(10.6-14.4)\end{array}$ \\
\hline & Women & $\begin{array}{l}15.9 \\
(14.8-17.1)\end{array}$ & & $\begin{array}{l}7.7 \\
(6.1-9.6)\end{array}$ & $\begin{array}{l}8.7 \\
(7.8-9.6)\end{array}$ & $\begin{array}{l}7.5 \\
(6.2-9.1)\end{array}$ \\
\hline \multirow[t]{2}{*}{$\begin{array}{l}\text { Condom use last higher } \\
\text { risk sex }\end{array}$} & Men & $\begin{array}{l}39.7 \\
(36.2-43.3)\end{array}$ & & $\begin{array}{l}38.9 \\
(33.4-44.7)\end{array}$ & $\begin{array}{l}42.9 \\
(38.5-47.4)\end{array}$ & $\begin{array}{l}41.6 \\
(36.3-47.1)\end{array}$ \\
\hline & Women & $\begin{array}{l}20.4 \\
(17.9-23.1)\end{array}$ & & $\begin{array}{l}31.2 \\
(24.5-38.8)\end{array}$ & $\begin{array}{l}33.3 \\
(29.5-37.3)\end{array}$ & $\begin{array}{l}34.6 \\
(28.3-41.5)\end{array}$ \\
\hline \multirow[t]{2}{*}{$\begin{array}{l}\text { More than one partner } \\
\text { in last year }\end{array}$} & Men & $\begin{array}{l}34.9 \\
(32.1-37.8)\end{array}$ & & $\begin{array}{l}19 \\
(16.2-22.1)\end{array}$ & $\begin{array}{l}20.7 \\
(18.7-22.9)\end{array}$ & $\begin{array}{l}12.8 \\
(11.0-14.7)\end{array}$ \\
\hline & Women & $\begin{array}{l}4.4 \\
(3.8-5.0)\end{array}$ & & $\begin{array}{l}2.4 \\
(1.8-3.3)\end{array}$ & $\begin{array}{l}2.1 \\
(1.7-2.5)\end{array}$ & $\begin{array}{l}2.1 \\
(1.5-2.9)\end{array}$ \\
\hline \multirow{2}{*}{$\begin{array}{l}\text { Sex with >1 partner in } \\
\text { last year; no condom } \\
\text { last time }\end{array}$} & Men & $\begin{array}{l}20.9 \\
(18.8-23.3)\end{array}$ & & $\begin{array}{l}14.3 \\
(11.9-17.0)\end{array}$ & $\begin{array}{l}15.4 \\
(13.7-17.2)\end{array}$ & $\begin{array}{l}10.2 \\
(8.7-11.9)\end{array}$ \\
\hline & Women & $\begin{array}{l}2.8 \\
(2.4-3.3)\end{array}$ & & $\begin{array}{l}1.9 \\
(1.3-2.6)\end{array}$ & $\begin{array}{l}1.6 \\
(1.3-2.0)\end{array}$ & $\begin{array}{l}1.6 \\
(1.1-2.3)\end{array}$ \\
\hline
\end{tabular}

Numbers in parenthesis show $95 \%$ confidence interval. 
Table 3 Results of multivariate analysis of changes in sexual behaviour indicators between 1996 and 2003, by calendar year and type of survey

\begin{tabular}{lllll}
\hline Sexual behaviour indicators & & OR* & $95 \%$ CI & p Value \\
\hline Men & & & & \\
Ever had sex (15-24 year olds only) & Calendar year & 0.95 & $(0.91-0.99)$ & 0.027 \\
& DHS $v$ SBS & 1.86 & $(1.49-2.32)$ & 0.000 \\
Had sex by age 15 & Calendar year & 0.93 & $(0.91-0.96)$ & 0.000 \\
& DHS $v$ SBS & 1.40 & $(1.19-1.64)$ & 0.000 \\
$>1$ partner in last year, did not use & Calendar year & 0.92 & $(0.89-0.95)$ & 0.000 \\
condom at last sex & DHS $v$ SBS & 1.30 & $(1.06-1.59)$ & 0.011 \\
Non-cohabiting partner in last year; no & Calendar year & 0.96 & $(0.92-0.99)$ & 0.017 \\
condom at last sex with that partner & DHS $v$ SBS & 1.80 & $(1.46-2.22)$ & 0.000 \\
Women & & & & \\
Ever had sex (15-24 year olds only) & Calendar year & 0.98 & $(0.95-1.01)$ & 0.142 \\
& DHS $v$ SBS & 1.17 & $(0.97-1.41)$ & 0.107 \\
Had sex by age 15 & Calendar year & 0.96 & $(0.94-0.98)$ & 0.000 \\
& DHS $v$ SBS & 1.54 & $(1.36-1.74)$ & 0.000 \\
Sex with $>1$ partner in last year, no & Calendar year & 0.89 & $(0.85-0.94)$ & 0.000 \\
condom at last sex & DHS $v$ SBS & 0.90 & $(0.65-1.26)$ & 0.553 \\
Non-cohabiting partner in last year; no & Calendar year & 0.85 & $(0.83-0.88)$ & 0.000 \\
condom at last sex with that partner & DHS $v$ SBS & 1.15 & $(0.93-1.42)$ & 0.193 \\
\hline
\end{tabular}

*Odds ratios (OR) are also adjusted for age, education (none, primary, secondary, higher), marital status (never, currently, formerly), current employment, and rural residence.

in the proportion of women who have not had sex in the last year, and in the proportion who have had sex with a cohabiting partner only and who used a condom the last time.

The proportion of all men engaging in the highest risk behaviour ( sex with a non-cohabiting partner in the last year without using a condom on the most recent occasion) has decreased over the period of interest from 25\% in 1996 to $20 \%$ in the 2001-2002 DHS and 12\% in the 2003 SBS. This decline has not been brought about by increases in the level of condom use by men who have sex with non-cohabiting partners. In each survey about $40 \%$ of these men report using a condom the last time they had sex with their noncohabiting partner (table 2). The change has occurred because fewer men are having sex, and of those who are having sex an increased proportion are reporting having sex with a cohabiting partner only in the year prior to the survey.

For both men and women the differences between the 1996 and 2003 surveys are most pronounced among those aged less than 25 years ( these are shown in fig 3 ). The difference between survey years in the proportion of people reporting sex with a non-cohabiting partner in the last year and not using a condom on the most recent occasion with this partner (the highest level of risk in this classification), was confounded by demographic factors which also changed between surveys. Multivariate analysis (see table 3 ) reveals a significant change in this indicator for both men and women; the odds of reporting this behaviour decreased by $4 \%$ each year for men and 15\% for women compared with the previous year.

Abstinence, number of partners, and condom use Another way to describe the survey sample is by the number of partners reported in the year prior to the survey and by condom use at last sex. This captures three behaviours often

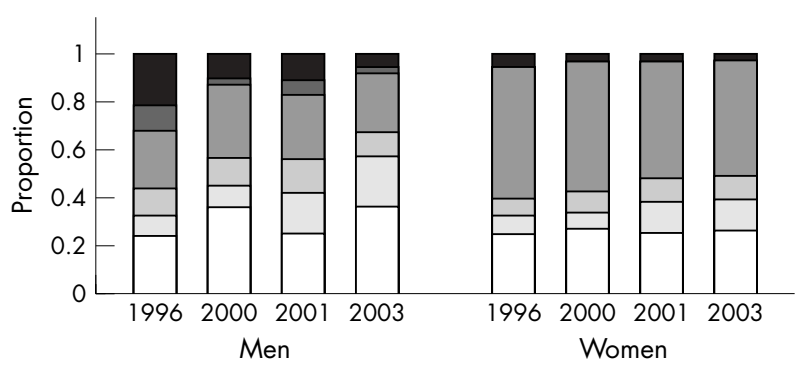

Proportion of all young people who, in the last year had:

Sex with non-cohabitating partner, no condom last time

$\square$ Sex with non-cohabitating partner, condom last time

$\square$ Sex only with cohabitating partner, no condom last time

Sex only with cohabitating partner, condom last time

No sex last year

Never had sex

Figure 3 Young people's sexual behaviour 1996-2003: sex and condom use with cohabiting and non-cohabiting partners.

promoted by AIDS prevention programmes: Abstinence, Being faithful, and using Condoms (ABC).

This distribution is different for men and women and for different age groups. In 1996 most women had only one partner in the year before the survey and did not use a condom the last time they had sex. A very small proportion of women had more than one partner and fewer than $10 \%$ of those used a condom the last time they had sex. Men in 1996 were much more likely to report having had sex with more
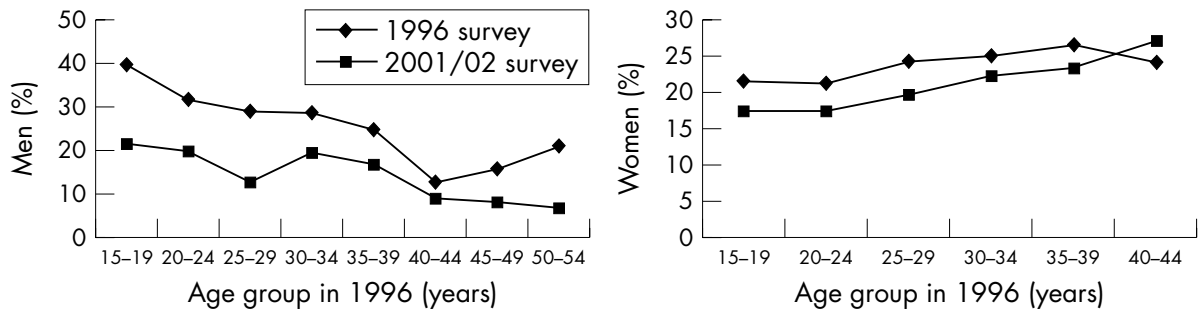

Figure 2 Percentage who reported having had sex by the age of 15 in 1996 and in $2001 / 2$, based on the age groups of the respondents at the time of the 1996 survey. 
than one partner in the last year-about $30 \%$ of men in the younger age groups-but were also more likely to have used a condom the last time they had sex.

The small proportion of women in 1996 who had sex with more than one partner was even lower in 2003 in all age groups $(3.5 \% v 2.1 \%)$, as was the proportion doing so without using a condom the last time they had sex $(2.8 \% \vee 1.6 \%)$; these results are given in table 2 . The proportion of men who reported having more than one partner in the 12 months before the survey was substantially lower in 2003 compared with 1996 (12.8\% $\vee 29.1 \%$; see table 2). In 2003 more 1519 year old men were reporting not having started sex, and this accounted for most of this change. In the older age groups greater numbers reported having had sex with only one partner in the year preceding the survey. Again changes are most evident among young people, as illustrated in figure 4 .

Controlling for potential confounders, the change in the size of the group at most risk (more than one partner in the last year and did not use a condom at last sex) was assessed (table 3). The results indicate a significant change in the level of this behaviour between 1996 and 2003 for both men and women. The decline in women's reporting was steeper than men's (odds ratio $0.89 v 0.92$ ). It appears that this trend is not an artefact of differences in the composition of the samples.

\section{DISCUSSION}

These survey samples differ significantly in the sociodemographic composition and in the sexual behaviours reported by their respondents. Once the confounding effects of sociodemographic factors have been accounted for significant differences remain in the reported behaviours of survey respondents from 1996 to 2003 . These changes are encouraging because all suggest reductions in risk behaviour.

The reported behaviours of men and of women have not changed in the same way. Declines in risk behaviour among one sex do not have to be mirrored by declines in the same behaviour among the other sex. Men and women do not choose partners in the same way. For example, women may choose partners older than themselves; men may have sex with sex workers. Therefore it is possible that men's risk behaviour can decline more than women's, or vice versa.

However, there may be alternative explanations for these changes. The survey instruments were similar but not

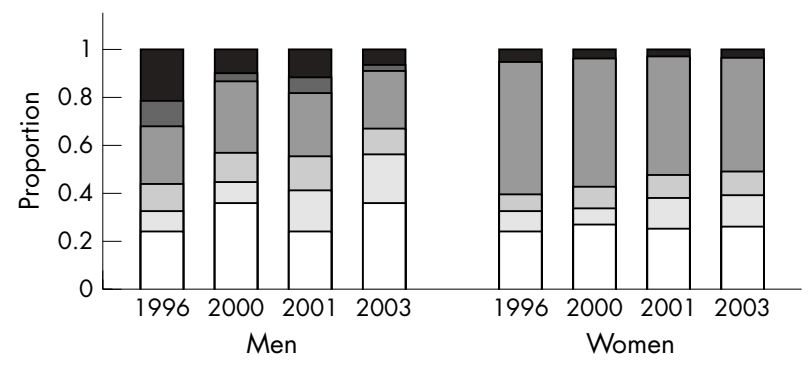

Proportion of all young people who, in the last year had:
Sex with $>1$ partner, no condom last time
Sex with $>1$ partner, condom last time
Sex with only one partner, no condom last time
Sex with only one partner, condom last time
No sex last year
Never had sex

Figure 4 Young people's sexual behaviour 1996-2003: abstinence, number of partners, and condom use at last sex $(A B C)$. identical. It is possible that the changes were observed because respondents reacted in different ways to the different questionnaires. It is also possible that, as a result of HIV prevention activities, respondents in later surveys were more aware of which behaviours presented an HIV risk and were more reluctant to report these behaviours, even if they had engaged in them.

These surveys have identified a change in the propensity to report early sex between 1996 and 2003. There may have been a change in willingness to report other behaviours perceived as undesirable but it is not possible to assess this for other measures of behaviour. The results of the 2001-2002 DHS indicate higher levels of risk behaviour among men than the results of either the 2000 or 2003 SBS. The results of the multivariate analyses show that men were still more likely to report each risk behaviour in the DHS after controlling for other factors (table 3). Women were more likely to report early sex in the DHS but there was no significant difference for the other risk behaviours. There are two possible explanations for this. The first is that the DHS locates a different sample of men than the SBS. This is plausible because different methods are used to select the men for the two types of survey. There may be a participation bias because agreeing to answer a survey about fertility and family formation could be easier than agreeing to a survey on sexual behaviour and HIV. On the other hand the DHS takes longer to complete, which might have deterred potential respondents. Differences in participation may not be fully accounted for by controlling for sociodemographic differences.

The 2001 DHS included an HIV and syphilis testing module in the households selected for the men's sample. This was conducted separately from the individual interviews and HIV results were not linked to other information about participants. However this may still have affected participation in the survey. Higher levels of risk behaviour were reported in the 2001 DHS than in either the 2000 or 2003 SBS. The decline in risk behaviour between the 1996 and 2001 DHS is consistent with the trend seen in the three SBS. Therefore it seems unlikely that the inclusion of the HIV and syphilis testing in the 2001 DHS adversely affected the quality of data on risk behaviour.

The other possible explanation for the difference between the results of the DHS and SBS surveys is that there was more reporting bias in one type of survey. This is also plausible because the surveys used different questionnaires (only the 2000 and 2003 SBS are similar). If this is the explanation it is interesting that men are more affected because men's reporting is often thought to be more accurate than women's. The discrepancies seen here suggest that Zambian women report their behaviour more consistently than Zambian men. This does not of course indicate who is the more truthful.

\section{CONCLUSION}

Reported sexual risk behaviours have declined in Zambia between 1996 and 2003 for both men and women. The age at which women start to have sex has remained the same, but men are reporting a later age for first sex. The proportion of people reporting sex before the age of 15 has declined and, although some of this change is probably change in reporting rather than actual behaviour, it seems likely that the age of sexual debut is increasing. The proportion of men and women who had sex with a non-cohabiting partner in the year before the survey and who did not use a condom on the last occasion has declined between 1996 and 2003.

Different survey designs and questionnaire styles yield different results. AIDS prevention campaigns may have also changed the propensity of respondents to report some behaviours. However, the magnitude of the changes suggests 
that at least some reduction in sexual risk behaviour is likely to have occurred.

\section{CONTRIBUTORS}

ES carried out the analysis. BB was involved in the design of the surveys and provided the data for the 2003 survey. ES and BB wrote the paper.

\section{Authors' affiliations}

E Slaymaker, Centre for Population Studies, London School of Hygiene and Tropical Medicine, London,UK

B Buckner, Carolina Population Center, University of North Carolina at Chapel Hill, CA, USA

Competing interests: none.

\section{REFERENCES}

1 Fylkesnes K, Musonda RM, Sichone M, et al. Declining HIV prevalence and risk behaviours in Zambia: evidence from surveillance and population-based surveys. AIDS 2001;15:907-16.
2 Bloom S, Banda C, Songolo G et al. Looking for change in response to the AIDS epidemic: trends in AIDS knowledge and sexual behavior in Zambia 1990 through 1998. J AIDS 2000;25:77-85.

3 Trends Report. AIDS in Africa during the nineties: Zambia (in press).

4 Central Statistical Office Republic of Zambia, Central Board of Health Republic of Zambia, Macro O. Zambia Demographic and Health Survey 2001-2. Calverton, Maryland. USA: Central Statistical Office, Central Board of Health and ORC Macro, 2003.

5 Central Statistical Office (Zambia), Ministry of Health (Zambia), Macro International Inc. Zambia Demographic and Health Survey 1996. Calverton, Maryland: Central Statistical Office and Macro International Inc, 1997.

6 Central Statistical Office (Zambia), Ministry of Health (Zambia), MEASURE Evaluation. Zambia sexual behaviour survey 1998 with selected findings from the quality of STD services assessment. North Carolina, USA: Chapel Hill, 1999.

7 Central Statistical Office (Zambia), Ministry of Health (Zambia), MEASURE Evaluation. Zambia sexual behaviour survey 2000. North Carolina, USA Chapel Hill, 2002

8 Central Statistical Office (Zambia), Ministry of Health, MEASURE Evaluation Zambia sexual behaviour survey 2003. Chapel Hill, North Carolina, USA: Central Statistics Office, Central Board of Health, MEASURE Evaluation Project, 2004

9 UNAIDS. National AIDS Programmes: a guide to monitoring and evaluation. Geneva: UNAIDS, 2000

10 Korn E, Graubard B. Analysis of health surveys. New York: John Wiley, 1999. 